This item was submitted to Loughborough's Research Repository by the author.

Items in Figshare are protected by copyright, with all rights reserved, unless otherwise indicated.

\title{
Digital laser-dyeing for polyester fabrics
}

PLEASE CITE THE PUBLISHED VERSION

http://dx.doi.org/10.2752/205117814X14228978833457

\section{PUBLISHER}

Taylor and Francis / @ Bloomsbury Publishing Plc

\section{VERSION}

AM (Accepted Manuscript)

\section{PUBLISHER STATEMENT}

This work is made available according to the conditions of the Creative Commons Attribution-NonCommercialNoDerivatives 4.0 International (CC BY-NC-ND 4.0) licence. Full details of this licence are available at: https://creativecommons.org/licenses/by-nc-nd/4.0/

\section{LICENCE}

CC BY-NC-ND 4.0

\section{REPOSITORY RECORD}

Akiwowo, Kerri, Faith Kane, John R. Tyrer, George W. Weaver, and Andrew Filarowski. 2019. "Digital Laserdyeing for Polyester Fabrics". figshare. https://hdl.handle.net/2134/18283. 
Journal of Textile Design Research and Practice

ISSN: 2051-1787, Online ISSN: 2051-1795

DOI: http://dx.doi.org/10.2752/205117814X14228978833457

Volume 02, Issue 02, pages 133-152

(C) 2014 Bloomsbury

\section{Digital Laser-dyeing for Polyester Fabrics}

Kerri Akiwowo; Faith Kane; John Tyrer; George Weaver; Andrew Filarowski

Kerri Akiwowo is a textile designer/researcher focusing on new processes and materials, existing and emerging technologies, smart fabrics, experimental textile printing, patterning, and surface design. She will complete her Ph.D. on digital laser-dyeing for polyester textiles in 2015. Faith Kane, John Tyrer, and George Weaver are academics based at Loughborough University in the fields of Textile Design, Optical Engineering, and Chemistry, respectively. Andrew Filarowski is Technical Director at the Society of Dyers and Colourists.

kerri.akiwowo@yahoo.co.uk

\section{ABSTRACT}

Surface polyester fibers modified by laser beam energy have been found to display improved dye uptake (Lau et al. 1997; Kamel et al. 2012; Shahidi et al. 2013). This research considers "laser-dye" patterning as an alternative coloration method within a textile design context. In this study, standardized polyester (PET) knitted jersey and plain, woven fabrics were modified with $\mathrm{CO}_{2}$ laser technology to engineer dye onto the fabric with high-resolution graphics. The work considered the aesthetic possibilities, production opportunities, and environmental potential of the process compared to traditional and existing surface design techniques. Laser-dyed patterns were generated by a digital dyeing technique involving CAD, laser technology, and dye practices to facilitate textile coloration and patterning. An understanding of energy density was used to define the tone of a dye in terms of color depth in relation to the cloth. In so doing, a system for calibrating levels of color against laser energy in order to build a tonal image was found. Central to the investigation was the consideration of the laser beam spot as a dots-per-inch tool, drawing on the principles used in digital printing processes. It was therefore possible to utilize the beam as an image-making instrument for modifying textile fibers with controlled laser energy.

Quantitative analysis of the outcomes alongside creative exploration facilitated both a tacit understanding of, and ability to control, 
processing parameters. This enabled repeatability of results parallel to design development and has established the potential to apply the technique commercially. Sportswear prototypes produced in the study suggest a suitable market for processing polyester garments in this way.

\section{Keywords}

textile design, $\mathrm{CO}_{2}$ laser technology, surface modification, laser-dye patterning, digital dyeing, textile coloration, polyester

\section{INTRODUCTION}

The effects of laser modification on the coloration properties of some synthetic fibers have been identified in previous academic studies such as Shahidi et al. (2013), Nourbakhsh and Ebrahimi (2012), Bahtiyari (2011), Yip et al. (2002), and Kan (2008a and 2008b). Current knowledge about laser-modified textiles centers on synthetic fibers regarding the effect on dyeing properties as investigated by Yip et al. (2002), for example. In particular, polyester/PET (Kamel et al. 2012) and polyamide/PA (Bahtiyari 2011). These polymer materials are preferable due to their affinity with laser irradiation. A reaction enabled by exposure to the beam changes their chemical-bond composition, which affects the dyeability of laser-treated surface fibers and results in improved color strength due to increased dye uptake. Conventionally, the coloration of synthetic textiles places high demand on resources such as energy and water use in processing and involves solvents, as documented by Shamey and Shim (2011). Laser technology, as a method of modifying surface fibers for dyeing, is a low-energy, dry, and efficient approach that does not involve chemicals and is therefore considered environmentally beneficial. Yip et al. (2002: 78), Shahidi et al. (2013: 42), and Wong et al. (2003: 114) further acknowledge such advantages of the process.

Scientific and technical approaches currently dominate this research area (Kan 2008a and 2008b; Nourbakhsh and Ebrahimi 2012). Investigation typically occurs in disciplines such as Textile Chemistry, Textile Engineering, and Material Science, for example. In these research contexts, an inherent scientific language has led to sufficient know-how of common issues regarding experimental methods, materials, data handling, and analysis. Investigation from within creative textile disciplines is apparent (Bartlett 2006; Addrison 2009) but is less developed from a scientific or technical perspective. Consequently, the "design potential" of a combined laser-dye process is limited. This Digital Laser-Dye study therefore addressed textile design aspects through surface pattern and color development within an interdisciplinary research framework combining creative, scientific, and 
technical methods to enable design innovation.

Traditional textile design and coloration methods facilitate creativity when applying color and pattern to fabric, as documented by Meller and Elffers (1991). Many textile designers and fabric producers embrace techniques based on conventions that are influenced by historical crafts, cultural references (Seivewright 2007), and current technology. Longestablished processes such as textile dyeing, printing, and pattern making, combined with advanced technologies like digital inkjet printing and laser technology, encourage opportunities for experimentation and innovation (Fish 2005: 81-90; Clarke 2011: 67; Bowles and Isaac 2012: 7). This approach often leads to novel patterning for textile surfaces and new fabrication ideas. Laser technology in particular enables alternative effects to traditional and existing textile patterning techniques and production methods.

The use of laser technology in textile design and manufacture to achieve a range of creative goals has increased in recent years (Gabzdy 2008: 21-2; Clarke 2011: 106-7, 130-1). At present, it is mainly used to cut and mark a range of textile materials for aesthetic effect. Designers and manufacturers have adopted laser processes to produce innovative materials that display the capability of the technology as a creative tool. In the textile industry, denim fabrics represent the vast majority of laser-etched goods (Lockman and Clayson 1996 and Ondogan et al. 2005). Laser cutting enables precise incisions with a variety of materials suitable for interior/exterior environments and the body, as explored by Boontje (Clarke 2011: 1067) and Hur (Global Colour Research Ltd 2009: 22; Braddock et al. 2012: 54), for example.

Within the textile design research communities, practitioners have used lasers to enhance the visual and tactile characteristics of cloth to create new structures and surfaces, often by combining conventional textile techniques with laser processing. For example, Goldsworthy (2009) employed laser technology as a creative, environmentally friendly alternative for finishing polyester substrates; Stoyel (1996 and 1999) explored laser technology for manipulating synthetic and natural fabrics for decorative surface effects in the form of patterns and textures; Matthews (2011) has developed novel laser processes to form threedimensional textiles; Schlaepfer et al. explore this technology as a tool for fine work to create laser-embellished metalized fabrics (Clarke 2011: 130-1); Kane (2008) has generated unique surface effects by integrating laser technology and nonwoven materials; Weedlun (2011) investigates laser engraving techniques for creating decorative, dualcolor appliqué textile designs; and Addrison (2009) and Bartlett (2006) began to combine surface modification methods with wet techniques. 
Both Addrison and Bartlett's work (2009 and 2006) reached a point that identified opportunities to achieve modified dye effects using the laser. However, the work was limited in terms of combining both creative and technical perspectives to achieve robust laser/dye processes for textile design and coloration development and also in terms of seeking an environmental/ecological relevance for the methods and findings.

The aim of this research was therefore to:

- $\quad$ explore a new laser-dye surface patterning method for textiles and investigate the design potential in integrating aesthetics, science, and technology;

- $\quad$ encourage innovative textile design and coloration approaches in a way that is commercially relevant and ecologically informed; and

- $\quad$ investigate digital laser-dyeing as a transferable, creative, graphic approach for textile designing with dyes.

In order to do this, a laser-dye process, using polyester fabric, was studied as an alternative textile coloration and patterning method to conventional approaches, so as to establish $\mathrm{CO}_{2}$ laser technology as a precise digital dyeing tool for textiles. As $\mathrm{CO}_{2}$ lasers are already used routinely within the textile industry, commercial exploitation of the research results is possible. ISO dyes and dyeing procedures were employed to further facilitate the commercial relevance of the research and to move the techniques forward from previous studies (Addrison 2009; Bartlett 2006) in which these procedures were not evident. The experimental results presented are based on energy-density parameters and color-calibration data. The purpose of this approach was to identify the creative opportunities of the process in a way that was commercially relevant in terms of reproducibility. The research was undertaken in collaboration with the Society of Dyers and Colourists (SDC) within the framework of an Arts and Humanities Research Council (AHRC [UK]) Collaborative Doctoral Award (CDA) as a means of supporting an industrial and commercial perspective on the work.

In this paper, the methodological approach is briefly outlined, specific experimental and design methods are described, key results are presented, conclusions are drawn, and further work is identified.

\section{METHODOLOGY}

An interdisciplinary approach was taken in which scientific inquiry, driven by design intentions, informed the textile design development. 
The process of doing research in this way is less traditional than that commonly relating to just a single discipline. Instead, as explained by Rhoten (2004: 6), a lateral and more fluid structure is adopted. Drake and Heath (2011: 61) allude to such fluidity as giving rise to "spaces created through the interaction of several 'contexts', which inevitably interact with each other." Such "spaces" can be perceived to encourage essential crossovers in thinking, discourse, and action, leading to "a more holistic outlook to problem solving" (Design Council UK 2010: 31) and creating platforms for innovation. This study combines creativity, technology, and science with industrial input (resources, facilities, expertise, and perspectives). The research involves methods from the disciplines of: textile design, optical engineering, dyeing chemistry, and color analysis. This approach echoes Anni Albers's comment on designing in 1947 (Albers 1962: 2):

we find two distinct points of departure: the scientific and technological, and the artistic. Too often these approaches arrive at separate results instead of a single, all-inclusive form that embodies our needs: the need for the functioning of a thing and the need for appearance that responds to our sense of form.

\section{EXPERIMENTAL METHODS AND APPROACHES}

As the term Digital Laser-Dye (DLD) suggests, the process involved combined CAD, laser technology, and dye practices. The experimental work reported upon here explored the technical parameters by which the process was essentially governed. It aimed to establish an understanding of the DLD process parameters in order to establish repeatable results.

Fabrics, laser-processing methods, dyes, dyeing procedures, and design aspects were explored. The work enhanced design capability through scientific understanding and integrated creative input, and the ability to replicate effects goes some way towards commercial validation of DLD where production reliability is paramount.

\section{Industry Standard Specification Fabrics}

The following ISO standardized specification fabrics were employed:

- Woven Polyester F ber: $100 \%$ polyester; Type:staple fber; Condition: undyed; Construction: 1/1 plain weave, warp: 23.5 per cm, weft: 20.5 per cm; Yarn: warp-7.5 tex Z 1000 X 2 S 800, R 15 tex; weft-20 tex S 800 
- $\quad$ Knitted Polyester F ber:97\% polyester $3 \%$ e lastane; Type: jersey knit; Name: BILLY; Condition: piece dyed off-white; Width:

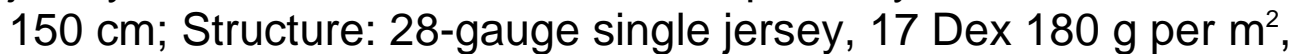
57 courses $-3 \mathrm{~cm}, 49$ wales $-3 \mathrm{~cm}$

Standardization ensured consistency between each fabric batch and individual test samples in relation to their unique specification data regarding fiber composition and textile construction.

\section{Laser Textile Processing: Defining Energy Density in this Study \\ "Energy density" describes the amount of power or joules/units of laser energy transferred to the fabric surface per $\mathrm{cm}^{2}$ via beam interaction, represented as $\mathrm{J} / \mathrm{cm}^{2}$. Figure 1 sets out an equation used to calculate energy density relevant to laser-treated textile samples.}

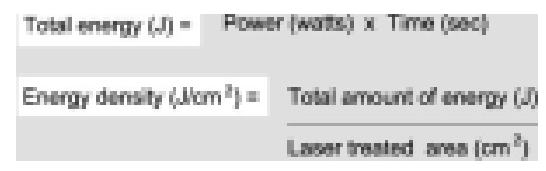

Figure 1

Figure 1

Energy-density equation. Photo: Kerri Akiwowo.

Actual power output was measured using a digital laser power meter-a 1-10 W Coherent LM10 Probe. This ensured accuracy when identifying and maintaining optimal processing energy to modify fabrics according to specific parameters and repeatable effects regarding patterning, dye uptake, and controlled surface treatment.

\section{LASER PATTERNING METHODS}

Digital laser-dyed patterns were formed with multiple dye tones generating a tonal spectrum. High-resolution capability of the laser beam spot when modifying textile fibers facilitated patterning likened to "dots-per-inch," as in digital printing processes. Two approaches were explored in this research-vector and raster laser beam scanning. Adobe Photoshop and Illustrator CAD software were used to create files and Image-Pro software was used for laser processing. 


\section{Vector Beam Scanning Method}

A vector method explored enabled consistent beam scanning in relation to a specified grid pattern. Linear vector grids were generated to provide a path or a type of "blueprint" for the beam to follow, different to relative beam scanning automation associated with raster methods. Vector lines were prepared using Adobe Illustrator CAD software compatible with the laser software.

Beam spot size was accounted for when applying a vector approach for laser processing. It was therefore possible to control beam overlap during scanning in order to determine even dye uptake on the textile surface. Level surface modification such as this is not always achievable with a beam overlap tendency in raster processing and can be difficult to avoid.

The consistent distance between repeated lines in a vector grid influenced energy density. Distances less than the beam-width diameter activated beam overlap, causing greater fiber/laser interaction and deeper dyeing as the fiber was modified twice. Larger gaps discouraged this effect, reducing interaction and encouraging weaker dye uptake. Subtler surface effects occurred due to reduced energy density. Therefore, a method for plotting energy density against tonal density was identified and a correlation between line space distance and color intensity was understood. This knowledge facilitated calibration values between vector line space distance (millimeters, $\mathrm{mm}$ ), total energy (joules, J), and energy density (joules per square centimeter, $\mathrm{J} / \mathrm{cm}^{2}$ ).

Incremental vector grid variables produced a relatively large tonal range from a dye. Results therefore indicate that a vector approach demonstrates a finely tuned affinity to the DLD process regarding tonal capability, identified in this study.

\section{Raster Beam Scanning Method}

A raster beam scanning method was capable of importing CAD files in the form of high-resolution shapes, patterns, and designs etc. into the laser computer software for processing. Essentially, a series of closely spaced parallel beam scans interacted with fibers by "filling" a predetermined area of the fabric in a continuous vertical zigzag motion.

Digital grayscale (GS) features linked to both CAD and laser software facilitated image depiction and variable modification levels to the textile surface. A grayscale design approach was explored in the development of graphics and engineered repeat patterns were initiated by combining CAD data with creative authority in the form of percentages of black (GS\%)-e.g. 50\%, 70\%, and so on. GS\% influenced energy density and, as such, this technique facilitated controlled variable power output 
in laser processing. When combined with specified laser parameters, this system determined differential dye uptake based on variable fiber modification linked to gray data.

Grayscale CAD designs were converted to halftone via laser software for raster scanning. Each GS\% generated a unique halftone, altering the energy density and power output of the laser beam during processing. Alternate fiber modification levels were enabled by this technique, and an understanding of actual power output in relation to design information (i.e. GS\%) and processing parameters such as energy in watts, velocity, spot size, etc. made it possible to digitally calibrate data to produce repeatable effects. Sufficient knowledge of the DLD process meant that the outcomes could be manipulated to alter surface treatment, color appearance, and patterning effects.

\section{Industry Standard Dyes}

ISO Itosperse disperse dyes were adopted for this research, consisting of shades:

- Yellow 3G

- Yellow Brown SERL 150\%

- Rubine CGL 150\%

- Red 2BE 200\%

- Blue 3RL 150\%

- Navy CD2G 200\%

In this paper, fabrics dyed with Blue 3RL $150 \%$ are presented and discussed.

\section{Industry Standard Dyeing Procedures}

Dry, laser-treated fabrics were dyed using ISO dyeing procedures. Dye baths were prepared from a $0.4 \%$ aqueous stock solution at a 1:9 dye/water ratio to achieve a $1 \%$ shade. $0.5 \%$ shade depths were also explored in this research. Deionized water was used to eliminate impurities. Auxiliary agents from a $0.4 \%$ stock solution were added to aid dye-to-fiber permeation at $0.5 \%$ on the weight of fabric. The $\mathrm{pH}$ acidity of each bath was maintained at 4.5 to ensure dye stability in terms of colorfastness.

Dyeing was carried out using a Coloursmith infrared dyeing machine. This machine type is routinely used in industry dye houses for sample dyeing. It is a low-liquor, controllable system capable of dyeing polyester at high temperatures. The machine facilitated batch dyeing, therefore multiple samples were dyed simultaneously in separate beakers. 
In this research, a high-temperature method was explored, in line with commercial requirements for the coloration of polyester textiles. An industry standard cycle for dyeing polyester was employed (Figure 2), reaching a maximum temperature of $140^{\circ} \mathrm{C}$. The dye bath and fabric sample were added to a beaker. Multiple beakers were then loaded inside the machine.

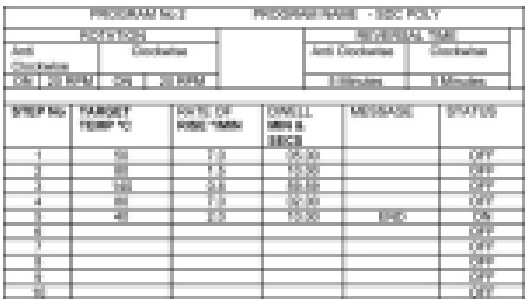

Figure 2

Figure 2

Polyester dye cycle used with infrared dye machine.

After dyeing, samples were rinsed in hot water and a reduction clearing after treatment was carried out. This procedure removed any unabsorbed dye by heating the fabric in $500 \mathrm{ml}$ of water containing $2 \mathrm{~g}$ of sodium hydrosulphite and $2 \mathrm{~g}$ of sodium hydroxide, compliant with ISO methods. The mixture was raised to $80^{\circ} \mathrm{C}$ and constantly stirred for 45 minutes to 1 hour. Afterwards, the sample was rinsed thoroughly in cold water until no trace of residual dye was found.

\section{QUANTITATIVE ANALYSIS}

Energy density, as described previously, was identified as a quantifiable method of calibrating laser power against levels of color, i.e. tones. An ability to know, understand, and manipulate energy output and distribution when processing a piece of fabric was fundamental to the digital laser-dye process. This concerned the raster and vector beam scanning approaches that were investigated. Mechanical know-how of methods enabled even, level dye uptake, making it possible to create a range of tonal densities using a single dye color in a way that could be repeated or altered by specification.

Initial experimental work undertaken did not consider an energy-density approach in terms of tonal variation. In this manner, outcomes occurred with no knowledge of how energy density and color density were relatable. This was problematic in terms of calibration. 
Not knowing the energy density required to produce a specific surface effect meant that the appearance of color/pattern was not attributed to laser power. Only a limited understanding linking a raster CAD approach to visual outputs was gained. Repeatability/reliability of the laser-dye process was therefore hindered due to a lack of information surrounding laser-processing parameters. This also presented disadvantages when considering transferability of the process using different $\mathrm{CO}_{2}$ laser machines operating at different powers. CAD files were significant here. Embedded design data determined modification levels and dye uptake on the fabric surface. Power parameters identified with a particular machine were different to those required for another. It was therefore essential to apply an energy-density approach in order to facilitate calibration in terms of processing and results.

Energy density provided a "common language" and quantifiable procedure for a digital laser-dye process in order to achieve controlled, repeatable tonal color range and pattern precision. In this research, an energy-density approach was established for both vector and raster beam scanning methods studied. As such, these procedures facilitated textile coloration and patterning via laser beam to determine dye uptake/shade depth variability with high-resolution graphics.

\section{DESIGN DEVELOPMENT AND PATTERN GENERATION}

In this research, textile design practice was approached as a "Tshaped" practitioner (Design Council 2010: 14). The characteristic "crossing over" from one distinct specialist area-Textile Design-into other disciplines, including Chemistry and Optical Engineering, together with industry involvement underpins the study.

A combination of hand-drawn material and CAD methods were used to formulate digital patterns towards final designs. Adobe Photoshop and Adobe Illustrator computer design software assisted this development. Computer graphics were interpreted via laser beam or spot to enable image creation with dyes. An ability to digitally generate and manipulate imagery as a textile designer specializing in print and surface pattern aided the designing stage.

The tonal capability of the laser process enhanced the appearance of patterns through an ability to achieve subtle, dramatic, or gradient shifts and shade depths on the cloth surface. Dye/color was imperative to the DLD process, primarily concerned with the coloration of laser-modified textile fibers via graphic methods. 


\section{RESULTS AND DISCUSSION}

By employing a linear vector grid method, a "colour chart" of 25 tones was generated using disperse dye Blue 3RL 150\% (Figure 3). Each tone represented a different grid pattern. Incremental differences to line spacing per grid began with a distance of $0.2 \mathrm{~mm} /$ Vector grid 1 , increasing by $0.01 \mathrm{~mm}$ through to $0.44 \mathrm{~mm} /$ Vector grid 25 . This system determined variable energy density, also achievable with different dye shades.

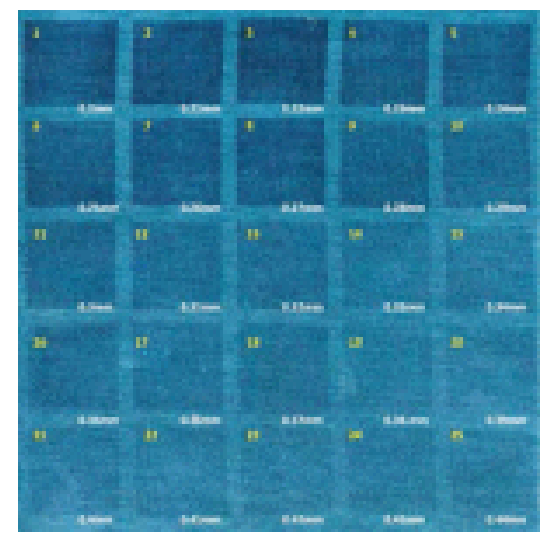

Figure 3

C lick to view

Figure 3

Laser-dyed tonal color chart: knitted polyester fabric sample.

A line spacing distance of $0.3 \mathrm{~mm} /$ Vector grid 11 matched the optimum focal beam diameter (also $0.3 \mathrm{~mm}$ ) for modifying polyester fabric, as investigated in this study. Within these parameters, beam overlap was avoided. Instead, energy output was evenly distributed across the textile surface during the scanning process. Alternatively, $0.21 \mathrm{~mm} /$ Vector grid 2 , for example, had a distance of less than $0.3 \mathrm{~mm}$. This relationship between beam and vector gridlines induced deeper dyeing due to greater fiber/laser interaction attributed to beam overlap. Significant spacing such as $0.43 \mathrm{~mm} /$ Vector grid 24 reduced interaction as the laser beam scanned the fabric less due to larger gaps between individual vector lines. Here, overall energy density was reduced, producing subtler surface effects linked to limited modification and consequently reduced dye uptake.

Table 1 shows the calibration values attributed to the fabric color chart (Figure 3 ) in relation to the laser processing parameters explored based 
on 4.5 watts (VV) of beam energy. Vector line space $(\mathrm{mm})$, Total energy $(\mathrm{J})$, and Energy density $\left(\mathrm{J} / \mathrm{cm}^{2}\right)$ values are given in relation to each digital laser-dyed area.

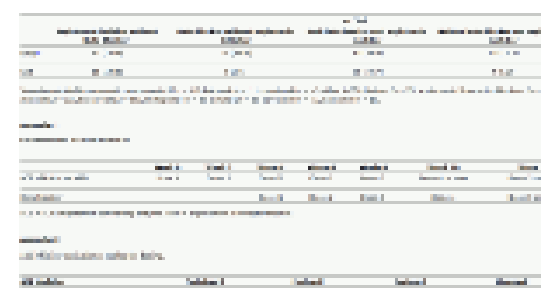

Table 1

Calibration values

The overall trend shows that energy-density values declined between grids 1 and 25 . The rate of change reflected marginal changes in line distance. It is therefore acknowledged that tonal variance was largely dependent on vector line spacing due to differences in laser power output between grid patterns. When referring to the fabric color chart, tonal density decreases as line-spacing distance increases. The greatest difference in energy density was recorded between Vector grids 1 and 25, which is understandable.

Color data was configured both visually and numerically, demonstrating the relationship between a specific vector grid, tonal density, and energy density (Figures 4 and $\underline{5}$ ).

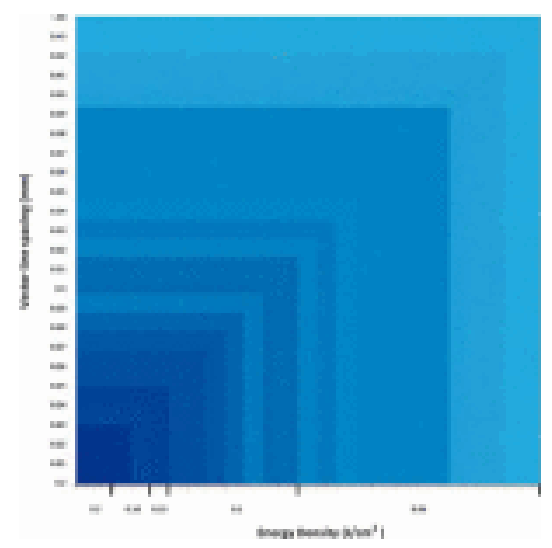

Figure 4 


\section{Figure 4}

Color-configured data: Energy density/Vector line spacing parameters.

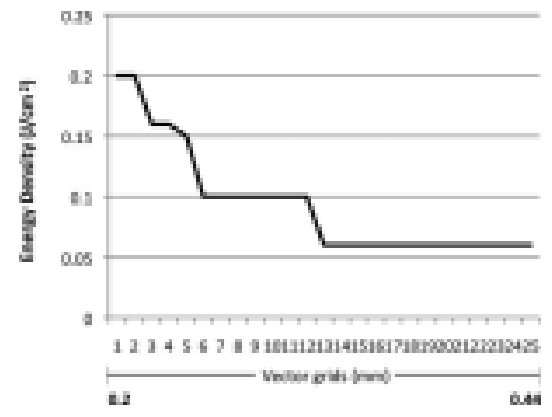

Figure 5

Figure 5

Graph showing an energy-density decline as line spacing increases per vector grid.

In order to build an image with variable tones, levels of color defined by energy density were employed. A grayscale raster approach enabled the formulation of graphics for textile patterning using a digital laser-dye process. Gray percentages (GS\%) were used to generate engineered repeat patterns. These patterns were translated creatively and quantitatively by combining design and technical data.

CAD files (Figure 6) determined the energy density required to achieve specific tonal effects (Figure 7) linked to other laser processing parameters such as actual output power/halftone pattern and velocity.

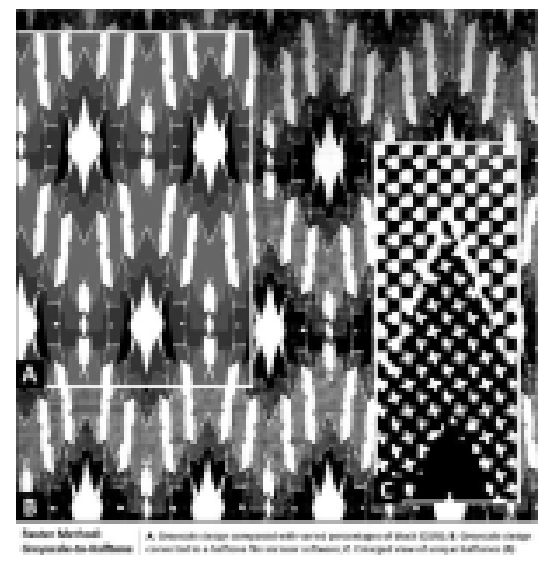

Figure 6 


\section{Figure 6}

Digital design file containing a range of gray tones (GS\%).

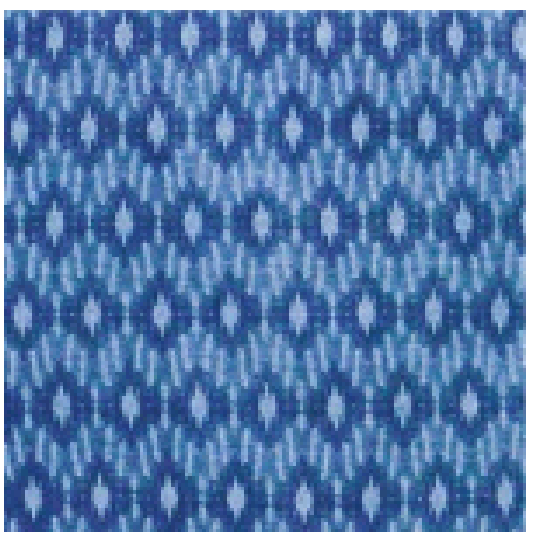

Figure 7

Figure 7

Digital laser-dyed knitted polyester textile sample.

Experimentation presented opportunities for processing finished garments (Figure 8). The laser beam was able to scan across seams and stitching while retaining high-resolution graphic qualities and tonal definition. This is not achievable with conventional image-based coloration approaches on to finished garments. With digital printing processes, the flat fabric is printed by the meter and the garment is constructed after printing and fixing the dye to the fabric. In screenprinting, the bulkiness of a finished garment when laid flat interferes with application and evenness of the print because the surface is not level. Garment dyeing typically involves total submersion of the item in a dye vat or equivalent container. These approaches do not facilitate patterning, focusing on coloration of the whole garment in a single, even shade to achieve a uniform distribution of dye color. As such, this work proposes a DLD system for textiles relevant to industrial manufacture and commercial goods. 


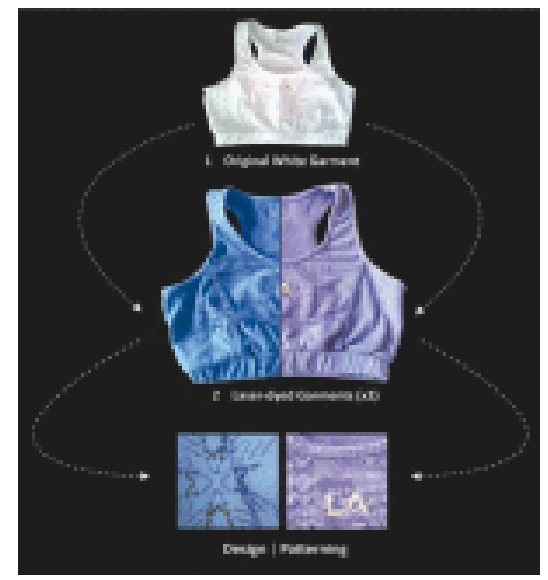

Figure 8

Figure 8

Digital laser-dyed sports bra tops.

\section{CONCLUSION AND FURTHER WORK TO BE UNDERTAKEN}

Digital laser-dyeing (DLD) explored in this study involved laser technology, CAD methods, and dyeing. This research assisted the development of textile coloration and patterning for PET textile materials. Knitted and woven fabrics as well as sportswear garments were studied. The interdisciplinary nature of the investigation facilitated textile design and apparel development. In doing so, this study has identified:

- $\quad$ a system for tonally varied dye uptake with high-resolution graphics based on an energy-density approach-a dexterous patterning tool that combines textile dyeing with CAD technology, integrating creative, technical, and scientific methods in order to suggest new reliable and repeatable surface effects/designs;

- new ways to process finished garments-combined patterning/coloration capabilities by means of laser marking/textile dyeing three-dimensional surfaces, proposing an "on demand" postproduction approach relevant to industrial manufacture and commercial goods; and

- environmental potential of the DLD process-a low-energy, lowresource approach requiring minimal or no chemicals, with the opportunity to reduce the conventionally high temperatures at which synthetic textiles are currently dyed in order to achieve satisfactory depth of shade. 
High-resolution capability was determined by combined laser, dyeing, and design parameters. This enabled variable dye densities by way of repeatable patterns with controlled laser energy. Creatively, the process enhances design qualities by encouraging new surface effects for textiles with dyes. Experimental investigation focused on process potential as an on-demand coloration tool for textiles with customization possibilities. As such, this approach is also considered relevant to the development of other fibers, textile structures, and dye types/shades.

A system for calibrating levels of color with graphics, against laser energy density in relation to a specific fiber (polyester) was established. In this manner, color data may be considered a type of "know-how guide" and model for laser processing textiles in this way. A formula for quantifying color in relation to the DLD process studied was achieved. This scientific approach supports the reliability and transferability aspects of the work.

Existing textile/laser studies regarding modification and dyeability do not evidence investigation into patterning or tonal dye distribution to such an extent. The current field of knowledge does not demonstrate "laserdyeing" in a way that is linked to energy density or to creative, digital, or industrial development of the process towards commercial application, as discussed in this paper.

The environmental opportunities of DLD processing for textiles relate to the low energy output of lasers and the absence of water and solvents in laser processing. Therefore the technology may be seen as an ecological alternative to traditional textile patterning techniques. An ability to achieve deep dyeing with digital laser-dyeing suggests the potential to reduce the high temperatures at which synthetic PET fabrics are conventionally dyed. This could potentially reduce energy consumption and negate the demand for additional chemicals used in printing processes, for example. These considerations are also acknowledged in previous work in this research field.

Further work aims to advance the design potential of the DLD process in terms of pattern and color development in relation to garmentfinishing opportunities. It will also aim to extend the eco capability of a laser-dye process integrating ecological assessment in practice, based on low water utilization and low energy processing factors in addition to functionality with regard to textile performance.

Different fiber types and fabric structures suggest the potential for new experimental surface effects, also relevant to textiles that have a mixed fiber content. Advances in computer software will aid pattern generation with vector methods, similar to the image-based capability of a raster approach. 
The customization possibilities and bespoke design potential for garments means that, in the long term, goods may be laser manufactured in bulk or small batches in advance and dyed on demand in response to orders, trends, markets, etc. For example, the potential to utilize laser-dyeing for stock, undyed garments could significantly impact retail environments. In turn, this would also reduce waste stock and manufacturing costs due to a "demand" approach, while enabling greater aesthetic flexibility. Production times from fabric to finished garment could be reduced, eliminating the need for multiple stages and excess resources in the chain. Commercially, the process would respond to a rapid retail landscape where production turnaround needs to be fast. In addition, environmental advantages would aid efficiency.

\section{REFERENCES}

1. Addrison J. 2009. In Cutting Edge: Laser and Creativity Symposium, Loughborough University, School of the Arts, 2009. Available at: cuttingedgesymposium.com/pdf/jenny-addrison.pdf.

2. Albers A. 1962. Anni Albers: On Designing. 2nd ed., Middletown, CT: Wesleyan University Press.

3. Bahtiyari M.I. 2011. "Laser Modification of Polyamide Fabrics." Optics \& Laser Technology, 43(1): 114-18.

4. $\quad$ Bartlett S.N. 2006. "Lasers and Textiles: An Exploration into Laser Dye-Fibre Interaction and the Process of Technology Transfer." Ph.D. thesis, Loughborough University.

5. Bowles M., and Isaac C. 2012. Digital Textile Design. 2nd ed., London: Laurence King Publishing.

6. Braddock E., Clarke S., and Harris J. 2012. Digital Visions for Fashion and Textiles: Made in Code. London: Thames \& Hudson.

7. Clarke S. 2011. Textile Design: Portfolio Series. London: Laurence King Publishing.

8. Design Council UK. 2010. Multidisciplinary Design Education in the UK, Final Report. London: Design Council UK.

9. Drake P., and Heath L. 2011. Practitioner Research at Doctoral Level: Developing Coherent Research Methodologies. London: Routledge.

10. Fish J. 2005. Designing and Printing Textiles. Marlborough: Crowood Press.

11. Gabzdy J. 2008. " Materials Processing: Fibre Lasers Make Their Mark." Nature Photonics, ( 2): 21-2, 23.

12. Global Color Research Ltd. 2009. "Wall Treatments: Monochrome Graphics." Mix: Color, Trend and Design Magazine: International Trends A/W 2010/11, 3 (17):22.

13. Goldsworthy K. 2009. "RESURFACED: Using Laser Technology to Create Innovative Surface Finishes for Recyclable, Synthetic 
Textiles." In Cutting Edge: Laser and Creativity Symposium, Loughborough University, School of the Arts, 2009. Available at: cuttingedgesymposium.com/pdf/kate-goldsworthypresentation.pdf.

14. Kamel M.M., Raslan W.M., Helmy H.M., and Al-Ashkar E. 2012. " Improving Properties of Polyester and Cellulose Acetate Fabrics Using Laser Irradiation." Journal of Textile Science and Engineering, 2:117. Available at: http://omicsgroup.org/journals/improving-properties-of-polyesterand-cellulose-acetate-fabrics-using-laser-irradiation-21658064.1000117. php?aid=9038. A downloadable PDF version is also available from the webpage.

15. Kan C.W. 2008a. "A Study of Laser Treatment on Polyester Substrates." Fibers and Polymers, 9(2): 166-70.

16. Kan C.W. 2008b. "Impact on Textile Properties of Polyester with Laser." Optics \& Laser Technology 40(1): 113-19.

17. Kane F. 2008. " Designing Nonwovens: Craft and Industrial Perspectives." Ph.D thesis, Loughborough University.

18. Lau KS., Chan P.W., Yeung K.W., Chan K., and Gong W.Z. 1997. "Surface Properties of Polyester Fabrics Induced by Excimer Laser Processing." Journal of Materials Processing Technology 63(1-3): 524-8.

19. Lockman W.J., and Clayson F.J. 1996. Method for Marking and Fading Textiles with Lasers. International classifications for the patent: D06C23/00, D06M10/00, D06P5/00, D06P5/20, D06B11/00, D06Q1/00. US classifications for the patent: 8/444; 8/115.52; 8/115.53.

20. Matthews J. 2011. "Textiles in Three Dimensions: An Investigation into Processes Employing Laser Technology to Form Design-led Three-dimensional Textiles." Ph.D. thesis, Loughborough University.

21. Meller S., and Elffers J. 1991. Textile Designs: 200 Years of Patterns for Printed Fabrics Arranged by Motif, Colour, Period and Design. London: Thames \& Hudson.

22. Nourbakhsh S., and Ebrahimi I. 2012. "Different Surface Modification of Poly (Ethylene Terephthalate) and Polyamide 66 Fibers by Atmospheric Air Plasma Discharge and Laser Treatment: Surface Morphology and Soil Release Behavior." Journal of Textile Science and Engineering, 2(109): 2. Available at: http://omicsgroup.org/journals/different-surface-modificationof-poly-ethylene-terephthalate-and-polyamide-66-fibers-21658064.1000109. php?aid=4539.

23. Ondogan Z., Pamuk O., Ondogan E.N., and Ozguney A. 2005. " Improving the Appearance of All Textile Products from Clothing to Home Textile Using Laser Technology." Optics \& Laser Technology, 37(8): 631-7. 
24. Rhoten D. 2004. "Interdisciplinary Research: Trend or Transition." Items and Issues, 5(1-2): 6-11.

25. Seivewright S. 2007. Basics Fashion Design 01: Research and Design. Lausanne: AVA Publishing.

26. Shahidi S., Wiener J., and Ghoranneviss M. 2013. Surface Modification Methods for Improving the Dyeability of Textile Fabrics. InTech. Available at:

http://www.intechopen.com/books/eco-friendly-textile-dyeing-andfinishing/surface-modification-methods-for-improving-thedyeability-of-textile-fabrics.

27. Shamey R., and Shim W. 2011. "Assessment of Key Issues in the Coloration of Polyester." Textile Progress, 43(2): 97-153.

28. Stoyel J. 1996. Method and Apparatus for the Manufacture of Textiles. References: UK classifications for this patent application (not patent): B3V VLC V202 V221 V231 V236 V255, B4B B70D. International classifications for the patent application: B23K 26/08.

29. Stoyel J. 1999. Manufacture of Textiles Using Ultrasound. UK classifications for the patent application (not patent): B3V V4BX, B4B B70D. International classifications for the patent application: 3/00, B23K 28/00.

30. Weedlun P. 2011. Appliqué Having Dual Colour Effect by Laser Engraving. International classifications for this patent: B32B37/02, B32B37/00, B32B38/04, B32B38/00, B32B38/00. US classifications for the patent: 156/253, 156/250, 156/256, $156 / 252$.

31. Wong W., Chan K., Yeung K.W., and Lau K.S. 2003. "Surface Structuring of Poly(ethylene terephthalate) by UV Excimer Laser." Journal of Materials Processing Technology, 132(1-3): 114-18.

32. Yip J., Chan K., Sin K., and Lau K. 2002. "UV Excimer Laser Modification of Polyamide Materials: Effect on Dyeing Properties." Materials Research Innovation, 6(2): 73-8. 